\section{Computing: report leaps geographical barriers but stumbles over gender}

SIR - As senior researchers in computer science, we were interested in both the report Towards 2020 Science, published by the Microsoft Corporation, and your related set of News Features and Commentaries (Nature $440,398-405$ and $409-419 ; 2006$ ). The vision of advanced computational techniques being tightly integrated with core science is an exciting and promising one, which we are glad to see being carefully explored and presented to the broader community.

We are, however, concerned that, of the 41 participants and commentators brought together by Microsoft, not one was female, with the same being true of the nine authors of the related articles in Nature. The report notes that the participants in the 2020 Science Group were geographically diverse, representing 12 nationalities, coming "from some of the world's leading research institutions and companies [and]... elected for their expertise in a principal field". Women have earned between $13 \%$ and $18 \%$ of all $\mathrm{PhDs}$ awarded in computer science and engineering in the United States during the past two decades. Women also work at leading research institutions, and also have expertise in the relevant fields. In most other scientific fields represented in the report, an even higher percentage of $\mathrm{PhDs}$ is female.

That the omission of women from the 2020 Science Group was doubtless unintentional does not lessen the negative message conveyed. The future of computing will be defined by the efforts of female as well as male computer scientists.

\section{Martha E. Pollack}

Computer Science and Engineering, University of Michigan, 2260 Hayward Street, Ann Arbor, Michigan 48109, USA

Susanne E. Hambrusch Purdue Lhiversity, USA

Carla Schlatter Ellis Duke Uhiversity, USA

Babara L. Grosz Harvard University, USA

Jessica Hodgins Carnegie Mellon Universky, USA

Ruzena Bajcsy Univesity of Collfamib, Berkeley, USA

Carla E Brodey Tu/s Univestity USA

Luigia Carlucci Aiello Unversitddi ioma La Sopienzo, Italy Maria Pada Bonacina Univesitd degli Studi d Verona, thaly LoriA Clate Unversity of Mossechusetts, Amberst, USA

Nila Hirschberg Columbia Unversity, USA

Manuela $M$ Veloso Cornegie Mellon University, USA

Nancy Amsto Tevos A\&M Unversity, USA

Liz Sonenberg Iniversity of Molbourne, Austraba

Elaine Weyuker AT\&I Labs USA

LoriPollock University of Deloware, USA

Mary Jane Irwin Pem State University USA

Lin Pad gham RMU T L Liversity, Australia

Baibara G. Ryder Rutgers University, USA

Tziana Catarci Universited di Rama La Sapienza, italy

Katheen F. MCCoy Unversity of Deloware, USA

Maria Klame Princeton Univershy, USA

Sandra Caberry Uhiversity of Deloware, USA
Laura Dillon Michigan State University, USA

Kathleen McKeown Calumbia University, USA

Mary Lou Soff L Lniversity of Virginia, USA

\section{Computer 'recycling' builds garbage dumps overseas}

SIR - Your Editorial "Steering the future of computing" (Nature 440, 383; 2006) explores the future potential of the computing industry. Interesting though this is, I am concerned by the millions of tonnes of electronic waste generated by the computer industry in the United States and other developed countries each year, much of which is being shipped for recycling in developing countries such as India, China, Bangladesh and Pakistan.

Cheap labour and weakenvironmental standards and law enforcement in developing countries attract high-tech garbage-dumping in the name of recycling. Old computers are being dumped or burned in irrigation canals and waterways across Asia, where they are releasing toxic substances such as lead, mercury, cadmium, beryllium and brominated flame retardants that pose serious health hazards to local people and the natural environment.

The 1989 Basel Convention, restricting the transfer of hazardous waste, has been ratified by all developed countries except the United States - which, according to the environmentalist report Exporting Harm (see www.svtc.org/cleancc/pubs/technotrash. htm), exports $50-80 \%$ of its computer waste. Many nations, including the European Union, have gone further and ratified an amendment banning all export of hazardous waste to developing countries. Those who have not should do more towards finding solutions for the safe disposal of accumulated hazardous waste on their own territory. G. Agoramoorthy Department of Pharmacy, Tajen University, Yanpu, Pingtung 907, Taiwan

\section{A logical alternative for biological computing}

SIR - Roger Brent and Jehoshua Bruck, in their Commentary article "Can computers help to explain biology?" (Nature 440, $416-417 ; 2006$ ), draw a firm distinction between von Neumann computers the usual computer as we know it - and biological systems. But there are many alternative models of computation. A Prolog (logic programming) computer, in particular, does not seem to exhibit several of the differences singled out.

A Prolog computation, like its biological counterpart, does not need an order of execution. Any partial ordering of the major components, known as clauses, are determined by a dynamic succession of pattern-matching operations. Within these clauses, the execution of logic expressions is unordered: $A$ and $B$ is the same as $B$ and $A$, and it does not matter whether we deal first with the truth of A or the truth of B (although computational constraints sometimes impose a partial ordering). A key for biological modelling would be to impose only those sequence constraints that have analogues in biological systems.

A second distinction highlighted by Brent and Bruck is that biological systems do not have a separate 'output' component. Again, Prolog does not conform to the norm. Often the important reason for executing a Prolog program is to find out what 'bindings' occur en route to a true outcome, in other words, what values are bound to what variables.

It is perhaps relevant that Stephen $\mathrm{H}$. Muggleton, in his companion Commentary article "Exceeding human limits" (Nature $440,409-410 ; 2006$ ), encourages the development of new formalisms within computer science that integrate mathematical logic and probability calculus.

Prolog may not be a perfect computational model for biological systems, but it exemplifies a system that could be a better fit for biological modelling. Derek Partridge School of Engineering Computer Science and Mathematics, Harrison Building University of Exeter, Exeter EX4 4QF, UK

\section{Colossus was the first electronic digital computer}

SIR - Your timeline ( ${ }^{\alpha}$ Milestones in scientific computing" Nature 440, 401-405; 2006) starts in 1946 with ENIAC, "widely thought of as the first electronic digital computer". But that title should arguably be held by the British special-purpose computer Colossus (1943), used during the Second World War in the secret code-breaking centre at Bletchley Park.

Modern computing history starts even earlier, in 1941, with the completion of the first working program-controlled computer Z3 by Konrad Zuse in Berlin. Zuse used electrical relays to implement switches, whereas Colossus and ENIAC used tubes. But the nature of the switches is not essential - today's machines use transistors, and the future may belong to optical or other types of switches.

Jürgen Schmidhuber

Dalle Molle Institute for Artificial Intelligence,

Galleria 2, 6928 Manno-Lugano, Switzerland, and Institut für Informatik, TUM, Boltzmannstraße 3, D-85748 Garching bei Mūnchen, Germany 